\title{
Etiología bacteriana de la diarrea aguda del lactante. Aportes de la inmunioflio- rescencia. Estudios de sensibilidad in vitro de los bacterios patógenos aislados
}

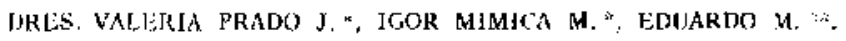

INTRODUCCIón. La diarrca es uno de Ios más importantes problentets médicos en nucstro país. Durante 1970, fallecieron por esta causa 4.608 personas, de las cuales $3.818(88 \%)$ fueron menores de un año.

Estamos conscientes que en su producción intervienen factores diversos y complejos: culturales. socioeconómico, higiénico sanitarios e infeccíosos. Pretendemos llegar a establecer con la mayor exactitud el papel de los agentes patógenos bacterianos dentro de este contexto.

Es de todos conocido el hecho que cl coprocultivo es de poca ayuda a la clínica en lo que respecta al diagnóstico etiológico de la diarrea, ya que por las curacteristicas de la muestra (flora asociada normal del intestino) metódica dificil y tiempo de elaboración que requicre, tiene por una parte un rendimiento polve y cuarndo permite aislar el agente patógeno, cste informe sólo sc obtiene a las 72 horas de sembrada la muestra, lo que retarda el tratamiento específico determinando agravamiento del cuadro clínico del enfermo en muches ocasiones.

Esto motiva, además, que por falta de tratatmiento etiológico oportuno en el paciente ambulatorio, el cuadto se haga más severo haciendo necesaria la hospitalización. Dentro del estáblecimiento hospitalario estos niños infictados al no ser detectado precozmente son punto de partida Je casos sccundarios intrahospitalarios prolongándose así su estadía con todos los inconvenientes que ello involucra y el ricsgo para la vida del enfermo.

Propósitos. Por tudos los antecedentes cnumeraldos quisimos desarrollar una técnica que permitiera efectuar un diagnóstico precoz de la ctiología de la diarrea con fínes terapéuticos y epidemiológicos.

\footnotetext{
" Deparlamento de Medicinak Expermmental. Unidad de Microblología. Aren Uriente.

* Jefe del Laboratorio de Bacleriología. Hospital Caltro Mackenna.
}

Ob.Jetros es? eciricos, 1. Desarrollar la tecnica de la immunofletorescencia aplicada al diagnóstico de Escherichia coli enteropatógeno (ECEP).

2. A través de esta técnica complementada con el coprocultivo. estudiar etiología bacteriana de la diarrea aguda con deshidratación en niños durante el período de diarrea estival 1971-1972 cn material del Hospital Calvo Mackenna.

3. Estudiar la sensibilidad in vitro de las cepass patógenas aisladas frente a difercntes agentes antimicrobianos.

Materias, y métonos. So prepararon 10 sueros anti ECEP. en concios de los signientes siro tipos: $026 \mathrm{~B} 6$ - $055 \mathrm{~B} 5$ - $086 \mathrm{~B} 7-0111 \mathrm{~B} 4$ 01122 B1I - $0119 \mathrm{~B} 14-0125 \mathrm{~B} 15-0126 \mathrm{~B} 16$ - 0127 B8 - 0128 B 12 .

Sc efectuó la conjugución de Ios antisueros con isotiocianato de flurresceina siguiendo la técnica descrita por Riggs.

1. Búsqueda de ECEP: A cirda muestra de deposición fresca se le cfectuó un test de T. F. directa poniondo en contacto frotis de la deposición con 3 cócteles conteniendo los 10 conjugados de sucro según técnica establecidas se consideró cono positivi la muestra que dio una fluorescencia de 3 o 4 cruces según nomenclatura internacional.

\section{Nomenclatura seguin intensidad:}

4 cruces: fluorescencia verde manzana briblante con formación de halo alrededor de los gémenes.

3 cruces: verde malzana vivo.

2 cruces: verde manzana pálido.

1 cruz: verde apenas visible.

0 : no se observa. 
Nomenclatura según el $N^{\circ}$ de organismos

observados.

4 cruces: más de 50 bacterios por campo o masas de bacterios.

3 cruces: 10 a 50 bacterios por campo.

2 cruces: 2 a 10 bacterios por campo.

1 cruz: 1 a 2 bacterios por campo.

0 : no se observan.

Aquellas muestras consideradas positivas se sembraron en agar SS y Maconkey para aislar la cepa respectiva.

2. Pesquisa de Salmonella y Shigella: Coprocultivo corriente. Se sembró una emulsión de la muestra en superficie en agar SS y Maconkey repicándose posteriormente a medios diferenciales.

3. Sensibilidad in vitro: se empleó la técnica de la C. I. M. por dilución en placa. Se estudiaron 45 cepas de ECEP y 9 cepas de Shigella frente a los siguientes agentes antimicrobianos:

Gentamicina - Neomicina sulfato - Furazolidona - Colistin sulfato - Tetraciclina - Cloramfenicol Ampicilina.

Materlal clínico. a) Se estudiaron 110 Tactantes con diarrea aguda con deshidratación, escogidos al azar, que ingresaron al Hospital Calvo Mackenna, en el período de verano 71-72.

A cada enfermo se le tomó 3 muestras de deposiciones en días sucesivos.

b) Se estudió un grupo control de 18 lactantes que no habían presentado diarrea en un período de 2 semanas anteriores al estudio.

T A B A No 1

FRECUENCIA DE AISI.AMIENTO DE BACTERIAS PATOGENAS EN HO LACTANTES CON DIARREA AGUDA.

\begin{tabular}{l|c|c}
\hline & $N^{0} \operatorname{casos}$ & $\%$ \\
\hline Bacterias patógenas & 67 & 60,9 \\
Bacterias no patógenas & 43 & 39,1 \\
\hline T o t a 1 & 110 & 100,0 \\
\hline
\end{tabular}

La tabla No 1 se expone el porcentaje de casos en los que se aisló bacterios patógenos específicos enterales. En un $60,9 \%$, el agente causal de la diarrea fue bacteriano.
TABLA No 2

DISTRIBUCION DE LAS BACTERIAS PATOGENAS AXSLADAS EN 67 CASOS DE DIARREA AGUDA BACTERIANA *

\begin{tabular}{lr|r|r|r}
\hline Etiología & $N$ & $\%$ & $N^{\varphi}$ & $\%$ \\
\hline A) Etiologia Monobacteriana & 62 & 92,5 & & \\
$\begin{array}{l}\text { Escherichia coli } \\
\text { enteropatógeno (ECEP) }\end{array}$ & & 55 & 82,0 \\
Shigella & & & 6 & 8,9 \\
Salmonella & 5 & 7,5 & & \\
\hline B) Etiologia Polibacteriana & 5 & & 3 & 4,4 \\
ECEP - Shigella & & & & 1,4 \\
ECEP - Salmonella & & & 2 & 3,3 \\
\hline
\end{tabular}

* La pesquisa de ECEP se efectuó por Inmunofluorescencia, La búsqueda de Salmonella y Shigella se hizo por Coprocultivo.

En la tabla $\mathrm{N}^{\circ} 2$ se señala el $\mathrm{N}$ o de enfermos con diarrea aguda de etiología, monobacteriana y polibacteriana.

TABLA No 3

TIPO Y FRECUENCIA DE LAS BACTERIAS PATOGENAS ENCONTRADAS EN G7 LACTANTES CON DIARREA AGUDA BACTERIANA.

\begin{tabular}{l|c|c}
\hline Bactcrio (cepa) & No & $\%$ \\
\hline ECEP & 60 & 84,5 \\
Shigella & 9 & 12,6 \\
Salmonella & 3 & 2,9 \\
\hline To t a 1 & 71 & 100,0 \\
\hline
\end{tabular}

En la tabla No 3 se analiza la frecuencia de los bacterios patógenos aislados en los 67 casos de diarrea de etiología bacteriana. Hay 71 cepas porque en 5 pucientes se aislaron 2 especies bacterianas al mismo tiempo. 
T A B I. A No 4

DISTRIBUCION SEGUN SEROTIPO DE 53 CEPAS DE ECEP EN 60 ENFERMOS CON DIARREA AGUDA POR ESTE BACTERIO

\begin{tabular}{c|r|r}
\hline Serotipo & $N^{\alpha}$ & $\%$ \\
\hline 0111 & 29 & 54,7 \\
0125 & 13 & 24,5 \\
0119 & 5 & 9,4 \\
055 & 2 & 3,7 \\
0127 & 2 & 3,7 \\
0126 & 1 & 0,7 \\
\hline Tot a I & 53 & 100,0 \\
\hline
\end{tabular}

En la tabla No 4 se destaca la frecuencia de jđentificación de los serotipos de ECEP. La tipificación de sueros mono específicos se efectuó en 53 de 60 muestras positivas. En 7 casos la identificación se hizo con sueros cócteles solamente.

T A B L A No 5

DISTRIBUCION SEGUN SEROGRUPO EN 9 CASOS DE SHIGELLOSIS

\begin{tabular}{l|l}
\hline Serogrupo & No \\
\hline Shigella flexnerii & 7 \\
Shigella boydii & 1 \\
Shigella sonnei & 1 \\
\hline T o t a 1 & 9 \\
\hline
\end{tabular}

T A B L A No 6

DISTRIBUCION SEGUN ESPECIE DE LA SALMONELLAS AISLADAS

\begin{tabular}{l|l}
\hline \multicolumn{1}{c|}{ Especie } & $N^{0}$ \\
\hline $\begin{array}{l}\text { Salmonella typhimurium } \\
\text { Salmonella bareilly }\end{array}$ & 2 \\
\hline To $\mathbf{~ a ~} 1$ & 3 \\
\hline
\end{tabular}

En las tablas No 5 y 6 se señala la frecuencia con que fueron aisladas distintas especies de Salmonella y Shigella desde coprocultivos en 110 lactantes con diarrea aguda.

T A B L A No 7

RELACION ENTRE POSITIVIDAD DEL TEST DE INMUNOFLUORESCENCIA Y EL NO DE MUESTRAS ESTUDIADAS EN $6 O$ ENFERMOS CON INFECCION ENTERAL POR ECEP.

\begin{tabular}{|c|c|c|c|}
\hline & $\mid N^{O}$ positivas $\mid$ & $\%$ & ${ }_{1} \%$ acumulato \\
\hline $1^{\text {a }}$ muestra & 35 & 59,3 & 59,3 \\
\hline $2{ }^{3}$ muestra & 19 & 30,5 & 89,8 \\
\hline 3a muestra & 6 & 10,2 & 100,0 \\
\hline Tot a l & 60 & 100,0 & \\
\hline
\end{tabular}

En la tabla No 7 se señala que 2 muestras por enfermo en días sucesivos dan un $89,8 \%$ de positividad.

TA BLA No 8

PORCENTAJE DE AISLAMIENTO DE LAS CEPAS DE ECEP EN EL COPROCULTIVO, EN RELACION AL TEST DE INMUNOFLUORESCENCIA

\begin{tabular}{c|c|c}
\hline No crifermos positivos & No cepas aisladas & to \\
\hline 60 & 45 & 75 \\
\hline
\end{tabular}

La tabla $N^{0} 8$ destaca el hecho que en un $25 \%$ el coprocultivo no permitió el aislamiento por Inmunofluorescencia.

TA B L A No 9

RESULTADO DEL TEST DE INMUNOFLUORESCENCIA IIF) DIRECTA EFECTUADO EN UN GRUPO CONTROL DE 18 NINOS SIN DIARREA

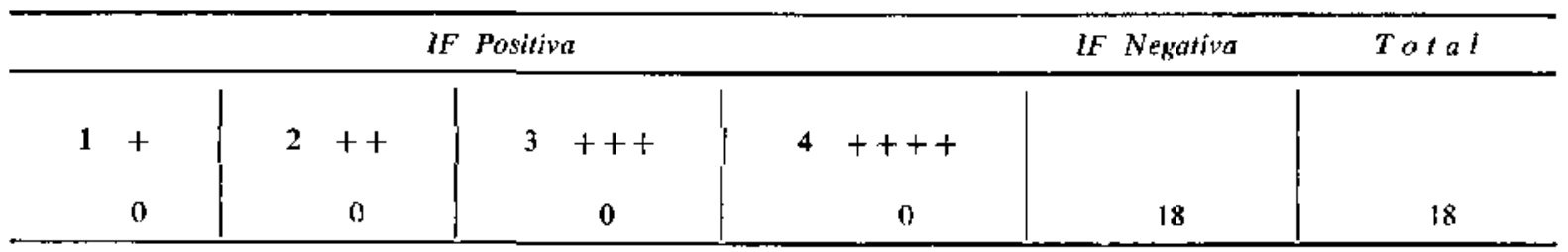

La tabla No 9 muestra los resultados de la $\mathrm{JF}$ en el grupo control. Ninguno de los niños sin diarrea presentan una IF positiva. 
T A B A No 10

SENSIBILIDAD IN VITRO DE 45 CEPAS DE ESCHERICHIA COLI ENTEROPATOGENO A GENTAMICINA

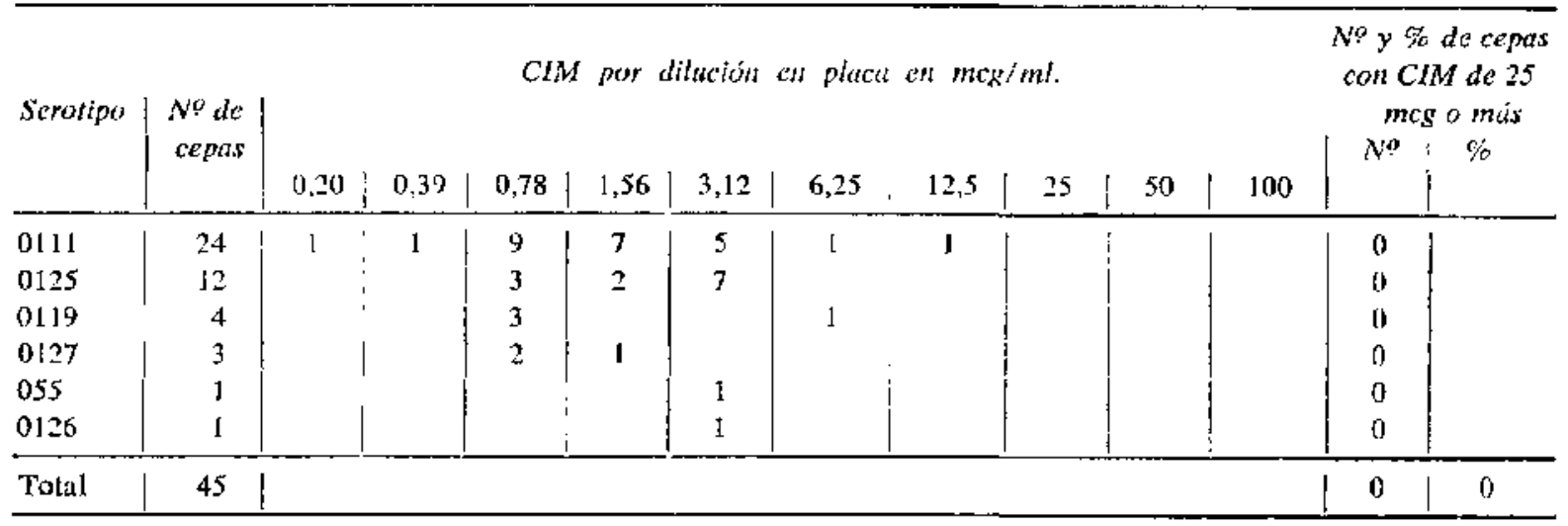

TABLA No I 1

SENSIBILIDAD IN VITRO DE 45 CEPAS DE ECEP A NEOMICINA

\begin{tabular}{|c|c|c|c|c|c|c|c|c|c|c|c|c|c|c|}
\hline \multirow[t]{2}{*}{ Serotipo } & \multirow[t]{2}{*}{$\begin{array}{l}N \text { de } \\
\text { cepas }\end{array}$} & & & 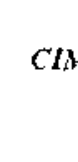 & $p o r$ & Iutión & " pitar & $c n+$ & $\mathrm{kg} / \mathrm{m}$ & & & & \multicolumn{2}{|c|}{$\begin{array}{l}N^{\circ} \text { y } \% \text { de } \\
\text { cepas con } \\
\text { CIM de } 50 \\
\text { mcg o más }\end{array}$} \\
\hline & & 0,20 & 0.39 & 0,78 & 1,56 & 3,12 & 6,25 & 12,5 & 25 & 50 & 100 & +100 & $N^{o}$ & $\%$ \\
\hline 0111 & 24 & & 1 & 3 & 3 & 3 & 6 & 1 & & 1 & & 6 & 7 & 29 \\
\hline 0125 & 12 & & & 1 & 5 & & 2 & & & & 2 & 2 & 4 & 33 \\
\hline 0119 & 4 & & & 2 & 1 & & & & & & & 1 & 1 & 25 \\
\hline 0127 & 3 & & & & 1 & 2 & & & & & & & & \\
\hline 055 & 1 & & & & & & & & & & & 1 & 1 & 100 \\
\hline 0126 & 1 & & & & & 1 & & & & & & & & 0 \\
\hline Total & 45 & & & & & & & & & & & & 13 & 28,8 \\
\hline
\end{tabular}

TAB L A N 12

SENSIBILIDAD IN VITRO DE 45 CEPAS DE ECEP A FURAZULIDONA

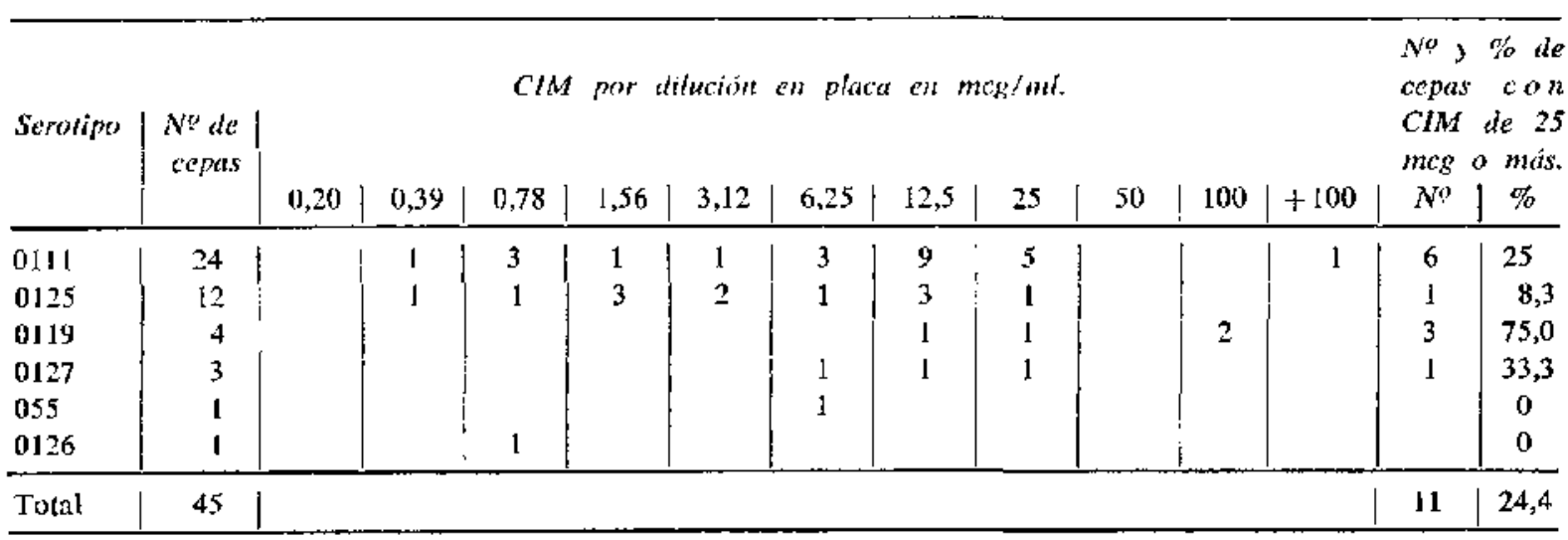


TAB L A No 13

SENSIBILIDAD IN VITRO DE 45 CEPAS DE ECEP A CLORAMFENICOL

\begin{tabular}{|c|c|c|c|c|c|c|c|c|c|c|c|c|c|c|}
\hline Serotipo & $\begin{array}{c}\text { No de } \\
\text { cepas }\end{array}$ & 0,20 & 0,34 & $C I M$ & 1,56 & dituciónt & $\begin{array}{l}\text { en plat } \\
6,25\end{array}$ & $\begin{array}{l}\text { en } \\
12,5\end{array}$ & $\begin{array}{l}m c g / m l \\
5\end{array}$ & ! 50 & 100 & $\begin{array}{r} \\
+100\end{array}$ & $\begin{array}{l}\text { No y } \\
\text { cepas } \\
\text { CIM } \\
m c g \\
N^{\prime}\end{array}$ & $\begin{array}{l}\% \text { de } \\
\text { con } \\
\text { de } 25 \\
o \text { más. } \\
\text { \% }\end{array}$ \\
\hline $\begin{array}{l}0111 \\
0125 \\
0119 \\
0127 \\
055 \\
0126\end{array}$ & $\begin{array}{r}24 \\
12 \\
4 \\
3 \\
1 \\
1\end{array}$ & & & & & I & 1 & & & 1 & & $\begin{array}{r}15 \\
8 \\
2 \\
1 \\
1 \\
1\end{array}$ & $\begin{array}{r}16 \\
8 \\
2 \\
1 \\
1 \\
1\end{array}$ & $\mid \begin{array}{r}66,6 \\
66,6 \\
50,0 \\
33,3 \\
100,0 \\
100,0\end{array}$ \\
\hline
\end{tabular}

TAB L A No 14

SENSIBILIDAD IN VITRO DE 45 CEPAS DE ECEP A TETRACICLINA

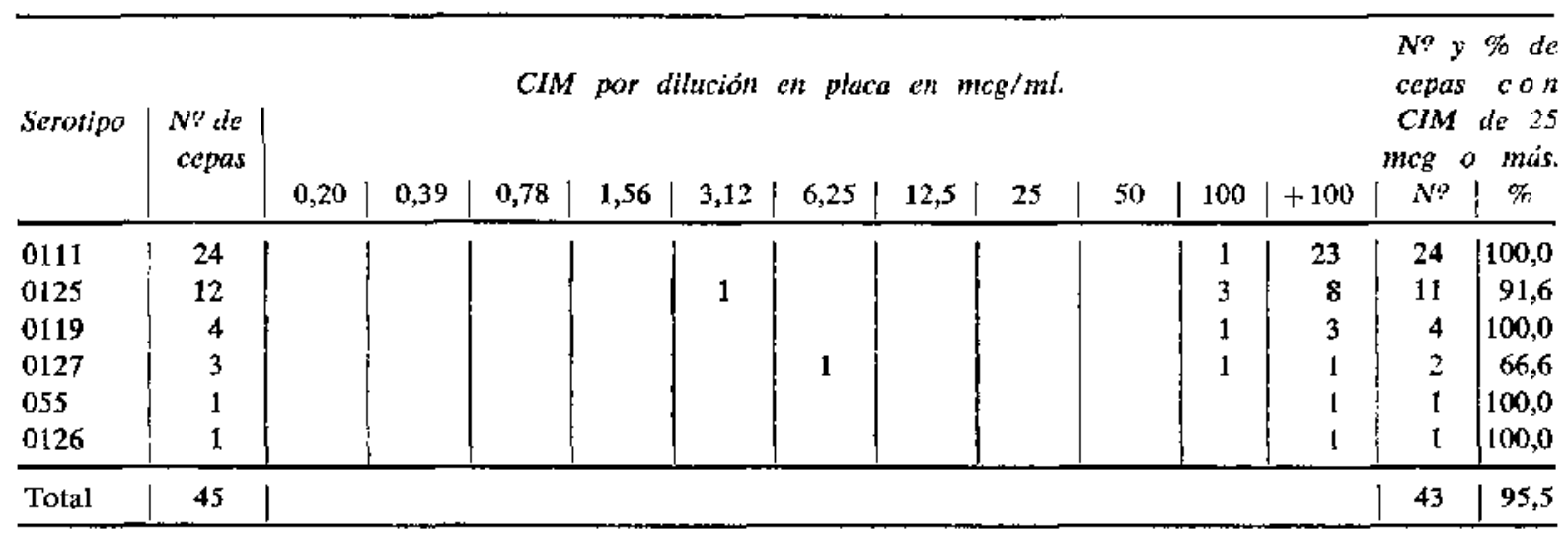

TABLA Nọ 15

SENSIBILIDAD IN VITRO DE 45 CEPAS DE ECEP A COLLSTIN SULFATO

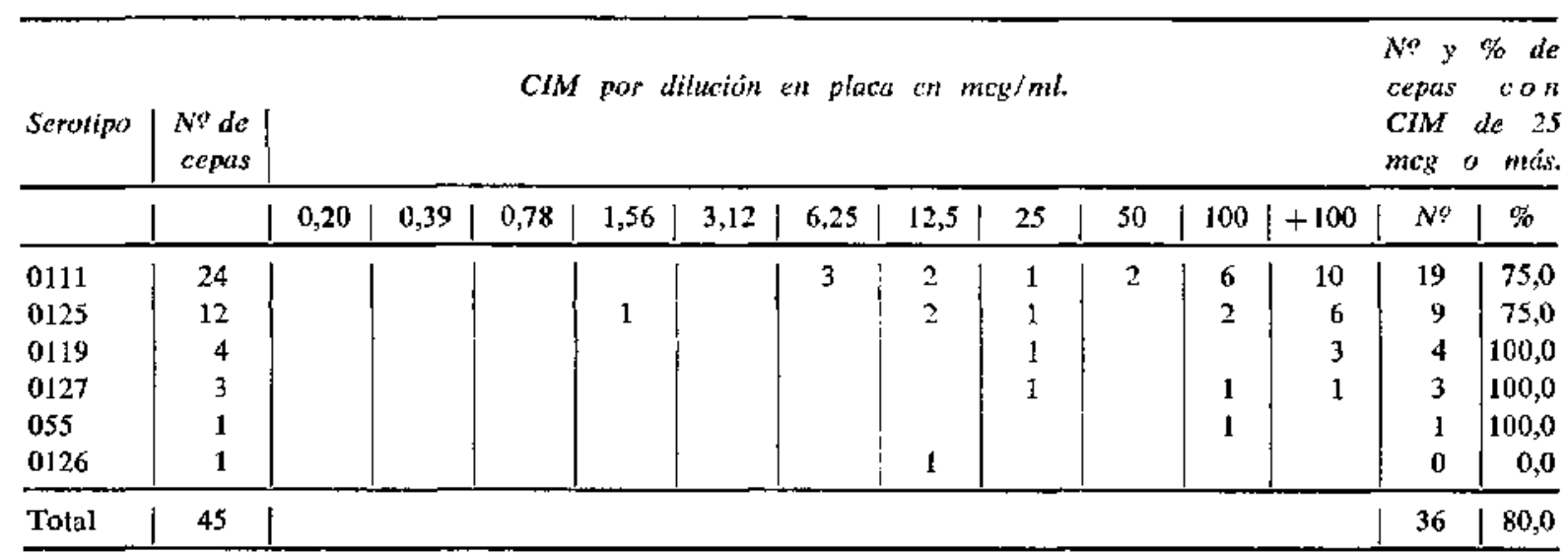


T A B L A No 16

SENSIBILIDAD IN VITRO DE 7 CEPAS DE SHIGEILA FLEXNERII FRENTE A 5 AGENTES QUHMIOTERAPICOS

\begin{tabular}{|c|c|c|c|c|c|c|c|c|c|c|c|c|c|}
\hline \multirow{2}{*}{ Antibiótico } & \multirow[b]{2}{*}{0,18} & \multirow[b]{2}{*}{0,18} & \multirow[b]{2}{*}{0.39} & \multicolumn{4}{|c|}{$\mathrm{C} M \mathrm{M}$ en $\mathrm{mcg} / \mathrm{ml}$. } & \multirow[b]{2}{*}{72,5} & \multirow[b]{2}{*}{25} & \multirow[b]{2}{*}{50} & \multirow[b]{2}{*}{100} & \multirow[b]{2}{*}{100} & \multirow{2}{*}{$\begin{array}{l}\text { Notal de } \\
\text { cepas y \% }\end{array}$} \\
\hline & & & & 0,78 & 1,56 & $3, I 2$ & 6,25 & & & & & & \\
\hline \multirow[t]{2}{*}{ Ampicilina } & & - & - & 4 & 1 & - & - & - & $\rightarrow$ & - & - & 2 & 7 \\
\hline & & & & 57,1 & 14.2 & - & & & & & & 28,5 & 100,0 \\
\hline \multirow[t]{2}{*}{ Furoxona } & - & - & - & - & $\ldots$ & - & 2 & 3 & - & 2 & - & - & 7 \\
\hline & & & & & & & 28,5 & 42,8 & & 28,5 & & & 100,0 \\
\hline \multirow[t]{2}{*}{ Gentamicina } & 7 & 一 & - & - & 一 & - & - & - & - & - & - & - & 7 \\
\hline & 100,0 & & & & & & & & & & & & 100,0 \\
\hline \multirow{2}{*}{$\begin{array}{l}\text { Cloram- } \\
\text { fenicol }\end{array}$} & I & - & - & 1 & - & 1 & - & 2 & $\ldots$ & - & - & 2 & 7 \\
\hline & 14,2 & & & 14.2 & & 14.2 & & 28,5 & & & & 28,5 & 100,0 \\
\hline \multirow{2}{*}{$\begin{array}{l}\text { Colistin } \\
\text { sulfato }\end{array}$} & 一 & - & - & - & - & 一 & - & - & - & 1 & 6 & - & 7 \\
\hline & & & & & & & & & & 14,2 & 85,7 & & 100,0 \\
\hline
\end{tabular}

En esta tabla se detalla la sensibilidad de las cepas de Shigella aisladás frevte a 5 antibióticos, expresados en base a CIM.

COMEntario. En este aspecto, básicamente destacamos la alta incidencia de bacterios patóge. nos específicos que demuestra nuestro estudio.

Hacemos prescnte que nuestro material, sin embargo, sólo consideró là población de lactantes hospitalizados por diarrea aguda con deshidratación, pero pensamos que estos casos reflejan lo que está sucediendo a nivel de la población general.

Con los resultados obtenidos a través de la inmunofluorescencia en $54 \%$ del total de lactantes estudiados encontramos ECEP. Esta cifra está muy por encima de lo publicado por autores cxtranjeros, especialmente norteamericanos, que emplean la misma técrica usada por nosotros. Esta diferencia puede explicarse al analizar las condiciones socioeconómicas de ambas poblaciones, ya que sabemos que las infecciones enterales están estrechamente ligadas a las condiciones higiénicosanitarias. Pero también la frecuencia de ECEP en nuestro material es superior a la encontrada en trabajos anteriores efectuados en población de la misma área. En este caso en que las características del universo estudiado eran similares, la variante importante era la técrica empleada ya que los datos anteriores se obtuvieron a través de coprocultivo $y$ vemos en el presente estudio que la técnica de la inmunofluorescencia aplicadá al diagnóstico bacteriológico es más sensible ya que nos permite la visualización directu de los bacterios. haciendo posible incluso la pesquisa de bacterios no viables que no son suceptibles de cultivo.

La gran disparidad de hallazgo entre coli patógeno, Salmonella y Shigella puede explicarse en parte porque no se empleó la misma técnica para la búsqueda de todos los bacterios patógenos.

La inmunofluorescencia se aplicó sólo al diagnóstico de ECEP en tanto que la pesquisa de Salmonella y Shigella se efectuó por el método clásico del coprocultivo, cl cual por las limitaciones de la técnica tienc menos rendimientos.

Otra ventaja de la técnica de la inmunofluorescencia que pudimos apreciar a través de nuestro estudio fue la importancia clínico epidemiológica de contar con un procedimiento que permita hacer ef diagnóstico etiológico precoz de la diarrea aguda.

Can la ayuda de la inmunofluorescencia dentro de las primeras 24 horas de ingreso se puede liegatr a identificar los enfermos con infección enteral por ECEP lo que posibilita acelerar la instauración de un tratamiento adecuado. Además permite efectuar aislamiento de los enfermos.

A nuestro juicio, esta característica, junto con la de permitir un diagnóstico más certero son las ventajas nás importantes sobre el coprocultivo, a través del cuill sólo al tercer o cuarto día de tonida la muestra se logra llegar a la identificación del bacterio patógeno cuando esto es posible. Además la inmunofluorescencia de acuerdo a la experiencia en nuestro país y de autores extranjeros permite la identificación del ECEP en un número de cásos que sobrepasa en dos veces el que permite el coprocultivo clásico.

La inmunofluorescencia resulta un método más práctico y de mayor rendimiento que el coprocultivo en lo que respecta a ECEP, este último a, nuestro juicio debe ser un complemento para los 
estudios biológicos y de sensibilidad de este grupo microbiano. Nuestra experiencia respecto a la frecuencia de los distintos serotipos de EC.EP encontrados coincide con los hallazgos anteriores en el país. También en publicaciones extranjeras el serotipo 0111 es el más frecuentemente detectado, que en nuestro material alcanzó un $54,7 \%$.

El otro serotipo de ECEP aislado con frecuencia fue el 0125 que alcanzó un $24,5 \%$ en coincidencia con Smith, Newell y Sulianti que también encontraron predominio de estos dos serotipos en una determinada área de EE.UU.

Un $60 \%$ de las diarreas por ECEP se diagnostican con el estudio de una sola muestra de deposiciones. El porcentaje asciende a casi el $90 \%$ cuando se estudia dos muestras en días succsivos, por lo que postulamos de acuerdo a nuestros resultados, que para tener un mayor éxito en la pesquisa de este bacterio debe estudiarse por lo me nos dos muestras de deposición cn días sucesivos aplicando el método de lat inmunofluorescencia. Esto se debe a que probablemente la eliminación de este patógeno entérico no es regular.

La frecuencia de aislamiento de otros bacterios patógenos entéricos: Salmonella y Shigella fuc ostensiblemente más bajo. Sin embargo queremos señalar que Shigella fue aislada en ef $8,1 \%$ de los niños estudiados to que constituye una frecuencia cuatro veces superior a lo referido en los últimos trabijos efectuatos en el área.

Por otra parte en esta serie de niños la frecuencia de aislamiento de salmonella fue de un $2,7 \%$, porcentaje que es algo más bajo que lo publicado en estudios anteriores en el área. Al respecto debemos destacar que la frecuencia relativa de aislamicnto de estos bacterios es variable de un año a otro, incluso es posible observar diferencias estacionales dentro de un mismo año, to cual reafirma nuestra creencia que los estudios en cuanto a etiología bacteriana de la diarrea deben ser repetidos en forma periódica.

En Shigella, el grupo más frecuentemente aislado fue el flexner como ha venido ocurriendo regularmente en nuestro país en los últimos años.

Respecto a las especies de Salmonellas aisladas queremos mencionar que las que con mayor frecuencia producen diarrea en el lactante en nuestro pais desde hace algunos años, son aquellas que constituyen zoonosis, especialmentc la Salmonella typhimurium lo cual se ha reafirmado en nuestro estudio.

En cuanto al estudio de sensibilidad in vitro frente a 6 agentes antimicrobianos: Gentamicina, Neomicina, Tetraciclina, Cloramfenjcol, FurazoJidona, Colistín sulfato.

De acuerdo a la información de nuestros resultados la Gentamicina resultó ser la droga más activa frente a ECEP in vitro, pues el $100 \%$ de las cepas tenían una CIM inferior a $25 \mathrm{mcg}$ por $\mathrm{ml}$, límitc establecido por Nealon para considerar sensible un ECEP a esta droga.

La Furazolidona demostró también buena actividad frente a ECEP y siguiendo el mismo criterio anterior un $75,6 \%$ de las cepas resultaron sensibles.

La Neomicina también mostró buena actividad resultando un $71,2 \%$ de las cepas sensibles, con una CIM inferior a $50 \mathrm{mcg}$. por $\mathrm{ml}$, límite de sensibilidad frente a esta droga.

EI resto de las drogas analizadas demostró escasa actividad frente a cste bacterio. En lo que se refierc a las ccpas de Shigella estudiadas, aun cuando el número de cepas es reducido, podemos decir que la Gentamicina mostró in vitro mayor actividad ya que el $100 \%$ de las cepas tenía una ClM inferior a $0,18 \mathrm{mcg}$ por $\mathrm{ml}$, en circunstancias que los niveles sanguíneos que se alcanzan con este antibiótico oscilan entre 2 y $3 \mathrm{mcg}$ por $\mathrm{ml}$. Frente a Ampicilina el 71,3\% de las cepas resultáron sensibles porque presentaron una CIM de $1,56 \mathrm{mcg}$ por ml. y los niveles sanguíneos que alcanza esta droga son del orden de $25 \mathrm{mcg}$ por $\mathrm{ml}$.

El resto de los antibióticos estudiados: Furazolidona - Cloramfenicol y Colistin sulfato demostraron poca efectividad in vitro frente a Shigella.

Conclusiones. Si se desea un control adecuado de la diarrea aguda del factante es imprescindible conocer la real etiología de este cuadro.

El uso de una técnica de mayor sensibilidad que el coprocultivo corriente y a este respecto la inmunofluorescencia directa ha demostrado ventajas en la identificación del ECEP, nos permite conocer en forma más real la frecuencia de los bacterios patógenos entéricos, procedimiento que si es empleado a nivel de una comunidad puede permitir una terapéutica y un control precoz y adecuado de esta enfermedad.

En cuanto a recursos terapéuticos el estudio de sensibilidad in vitro mostró que GentamicinaFurazolidona y Neomicina tienen buena actividad frente a coli patógeno. En los casos de Shigellosis las drogas que muestran mejor actividad in vitro frente al este bacterio son Gentamicina y Ampicilina.

\section{REsumen}

Se realiza un estudio de la etiología bacteriana de la diarrea aguda en 110 lactantes tomados al azar, a los cuales se les efectuaron 3 coprocultivos y 3 test de Inmunofluorescencia (I.F.) directa para ECEP. En un 60,9\% de los lactantes se aislaron bacterios patógenos específicos de las deposiciones. El agente patógeno aislado con mayor frecuencia fue el ECEP; $84,5 \%$, Shigellas se aistó en un 12,6\% y Salmonella 2,9\%. Se demuestran vemajas de la técnica de I.F. directa 
en ef diagnóstico bacteriano; mayor sensibilidad y rapide son la garantia de comple ta especificidad.

El estudio se sensibilidad "in vitro" de las cepas aisladas mostró que las drogas más efectivas frente a ECEP son; Gentamicina y Neomicina. Frente a Shigella di antibiótico de clección resultó ser Gentamicina y en segundo lugar Ampicilina.

\section{SUMMARY}

110 infants with acute diarrhea with dehidration were selected at random. Three stool cultures and fluorescent antibody test for $E$. coli were performed in the first three days after their hospitalization.

Pathogenic organism were isolated from stool cultures in $60.9 \%$ of the patients, of these pathogenic strains $84,5 \%$ were serotypes of $E$. coli; $12,6 \%$ were Shigella and $2.9 \%$ were salmonella.

The advantages of the fluorescent antibody technique are discussed. The conclusion is that method is quicker, more sensitive and with the warranty of being specific.

In vitro sensitivity lests of isolated strains demons. trated that against $E$, coli the most effective anlibiotics are Gentamicin and Neomycin for shigella these are Gentamicin and Ampicillin.

\section{REFEKENCIAS}

1.- Howard J. E., Beca J. P. Clinicalassesment of Hetacillin in acute diarrhsa of malnourrished infants. Annals of N. Y. Academy of Sciences 1967 vol. 145 art. 2. Pág. 436.
2.-Nelsom I. D. Whitaker J. A. E. coli diarrbea and fluorescein labelled antibodies. Pediatrics, november 1960 vol. 57 number 5 .

3.-Melindez M. Grove E., Cussorla R. Lobos H. y Jacob C. Diagnóstico de Escherichia coli enteropatógeno en diarreas infantiles por el método de Inmunofluorescencia. Rev, Chil. Ped. Marzo 1971 No 3.

4.-Cherry W. B. Thomason B. M. Fluorescent antibody technique for Salronellae and other enteric pathogens 1969 Oct Public Health reports vol. 84 , No 10 p. $887-889$.

5.-Smith-Newell and Sullianti. E. coli infection in non hospitalized children 1965. Antimicrobial agents and chemoterapy.

6.--South. Enteropathogenic E. coli. The Journal of Pediatrics July 197 I vol. 79 number 1.

7.-Neaion D. A. Mitcheil I. A. Martin L. Antimicrobial suceptibility patherns of entcropathogenic Escherichia coli isolated in the New Orleans area. Antimicrobial agents and chemotberapy 1965. Pág. 289.

8.- Nelson J. D. Halralin. In vitro suceptibility of E. coli, Shigellae and Salmonellas to Kanamycin and therapeutics implications. Annals of N. Y. Academy Of Sciences. June 1966 vol. 132. Pág. 10061014. 